DOI 10.37882/2223-2982.2021.12-2.34

\title{
ВОСПИТАТЕЛЬНЫЙ ПОТЕНЦИАЛ ДИСЦИПЛИНЫ «ГЕНЕТИКА» И ЕГО РЕАЛИЗАЦИЯ В СИСТЕМЕ ПРОФЕССИОНАЛЬНОЙ ПОДГОТОВКИ БУДУЩИХ УЧИТЕЛЕЙ БИОЛОГИИ
}

\section{UPBRINGING POTENTIAL OF THE DISCIPLINE "GENETICS" AND ITS \\ REALIZATION IN THE SYSTEM \\ OF PROFESSIONAL TRAINING OF FUTURE BIOLOGY TEACHERS}

A. Semenov

Summary: The article is devoted to the problem of professional training of future biology teachers to implement the educational function on the example of the course "Genetics». The work is based on the study and analysis of the literature on genetics and methods of its teaching. The article presents the content of the course of genetics, which can be used for the purpose of civil, patriotic, spiritual and moral, aesthetic, labor, environmental education, as well as the formation of a culture of health and values of scientific knowledge. The materials of the article are intended for university teachers of genetics, biology students of pedagogical education, methodologists, as well as school biology teachers.

Keywords: pedagogical education, teacher training, students, genetics, upbringing.
Семенов Александр Алексеевич

к.б.н., дочент, ФГБОУ ВО «Самарский государственный социально-педагогический университет»

semenov@sgspu.ru

Аннотация: Статья посвящена проблеме профессиональной подготовки будущих учителей биологии к реализации воспитательной функции на примере курса «Генетика». Работа выполнена на основе изучения и анализа литературы по генетике и методике ее преподавания. В статье приведено содержание курса генетики, которое может быть использовано с целью гражданского, патриотического, духовно-нравственного, эстетического, трудового, экологического воспитания, а также формирования культуры здоровья и ценностей научного познания. Материалы статьи предназначены для преподавателей генетики, студентов-биологов педагогического образования, методистов, а также школьных учителей биологии.

Ключевые слова: педагогическое образование, подготовка учителей, студенты, генетика, воспитание.

щих собой объединения высших учебных заведений, научно-исследовательских институтов, производственных и инновационных компаний [2].

Для создания прорывных генетических технологий нужны грамотные, высококвалифицированные специалисты, подготовка которых должна начинаться уже со школьной скамьи. В связи с этим, президентом страны поставлена стратегическая задача для современной общеобразовательной школы - формирование у подрастающего поколения стойкого интереса к генетике, стремления совершать новые открытия, быть первопроходцами [2]. С этой целью, помимо учебного предмета «Биология», рассматривающего основы генетики на базовом и углублённом уровнях, школьникам в 10 или 11 классах предлагается освоение самостоятельного курса «Генетика». Он в большей степени направлен на изучение молекулярной генетики, современных генетических технологий, достижений биотехнологии и генной инженерии, молекулярных методов диагностики и достижений медицинской генетики [3].

Нередко революционные и многообещающие откры- 
тия в генетике поднимают проблемы морально-этического плана, которые требуют своего решения. История знает немало случаев, когда сами ученые прекращали свои исследования, опасаясь за их негативные последствия [4]. Нельзя забывать о том, что современные генетические технологии в руках недобросовестных людей могут обернуться большими бедами. Поэтому помимо изучения основ генетики и генетических технологий в школе, следует уделять большое внимание воспитанию учащихся, формированию их духовно-нравственного облика, основанного на базовых национальных ценностях Российской Федерации - семья, труд, отечество, природа, мир, знания, культура, здоровье, человек [5]. Генетика как наука и учебная дисциплина предоставляет для этого широкие возможности, реализация которых возлагается на школьного учителя биологии.

Исходя из вышеизложенного, целью написания настоящей статьи стало выявление воспитательного потенциала воспитательного потенциала курса «Генетика» и его реализация в профессиональной подготовке будущих учителей биологии.

Обновленные федеральные государственные образовательные стандарты общего образования предполагают достижение личностных образовательных результатов в единстве двух процессов - обучения и воспитания. Личностные результаты отражают готовность учащихся руководствоваться системой позитивных ценностных ориентаций [6]. Следовательно, будущие учителя биологии должны быть готовы к реализации воспитательного потенциала своего предмета, в том числе основ генетики.

Одним из основных учебных курсов предметной подготовки бакалавров-биологов педагогического образования является «Генетика». Ниже рассмотрим его возможности в рамках основных направлений воспитания.

Гражданское воспитание - выполнение обязанностей гражданина и реализация его прав, а также уважение прав, свобод и законных интересов иных лиц.

Реализации гражданского воспитания способствует изучение в рамках курса генетики законодательной базы Российской Федерации в части государственного регулирования в области генно-инженерной деятельности [7], временного запрета на клонирование человека [8], биологической безопасности [9]; гражданского подвига советских генетиков (Н.И. Вавилов, Н.В. Тимофеев-Ресовский, Г.Д. Карпеченко) в годы сталинских репрессий и гонений на генетику во времена лысенковщины [10; 11]. Здесь следует отметить подвиг учёных Всесоюзного института растениеводства Н.И. Вавилова, которые сохранили уникальную коллекцию культурных растений, не употребив в пищу ни единого зернышка, ни одного картофельного клубня. Умирая от истощения во время блокады Ленинграда, они выполнили свой гражданский и профессиональный долг до конца.

Патриотическое воспитание - осознание российской гражданской идентичности, проявление интереса к истории отечественной генетики, формирование ценностного отношения к ее достижениям.

При изучении курса генетики патриотическому воспитанию содействует приобщение учащихся к истории российской генетики, в том числе на местном уровне, ее героических и трагических страниц; знакомство с биографиями и трудами отечественных ученых-генетиков, внесших существенный вклад в развитие генетики и генетических технологий. Среди них следует отметить Н.К. Кольцова, высказавшего гипотезу о матричном принципе репродукции гена; С.Г. Навашина, описавшего основные типы митотических хромосом растений; Н.И. Вавилова, создавшего учение о мировых центрах происхождения культурных растений, сформулировавшего закон гомологических рядов в наследственной изменчивости организмов; С.С. Четверикова, заложившего основы экспериментальной генетики популяций, которые легли в основу синтетической теории эволюции; Г.Д. Карпеченко, впервые получившего межродовые гибриды; Г.А. Левитского, предложившего понятие «кариотип»; Г.А. Надсона и Г.С. Филиппова, впервые индуцировавших мутации при помощи рентгеновских лучей; А.С. Серебровского и Н.П. Дубинина, впервые продемонстрировавших сложную природу организации гена; И.А. Рапопорта, открывшего химический мутагенез; Б.Л. Астаурова, заложившего основы теории регуляции пола [12]; Л.И. Лушину, самарского генетика, изучавшего мутагенное действие алкилирующих соединений на растения горох и пшеницу.

В настоящее время в области генетических технологий российскими учёными достигнуты значительные успехи. Так, в Институте молекулярной биологии РАН разработаны высокочувствительные средства выявления ВИЧ-инфекции, созданы штаммы модифицированных вирусов, которые способны убивать раковые клетки молочной железы и мозга. Им нет аналогов в мире. Они могут стать прорывными в лечении онкологических заболеваний. В планах - создать линейку генетических технологий в промышленности, медицине и экологии, в том числе национальную базу генетической информации [2].

Важным направлением биомедицинских наук в России стала эпигенетика, изучающая механизмы наследственности, несвязанные с последовательностью ДНК. Российскими учёными изучены эпигенетические изменения, вызванные стрессами, полученными в раннем детстве, и процессами, протекающими в ходе нормативного старения. Специалисты доказали, что недоста- 
точность родительской опеки в раннем возрасте может отразиться на развитии, физическом и психическом здоровье детей, а снижение у них высших когнитивных функций в старости может быть связано с общим понижением экспрессии генов в коре головного мозга [13].

Духовно-нравственное воспитание - ориентация на моральные ценности и нормы в ситуациях нравственного выбора, касающихся вопросов генетики и использования генетических технологий, активное неприятие асоциальных поступков.

К числу морально-этических проблем генетики относятся работы по генной инженерии, клонирование человека, рождение детей из пробирки и от трёх родителей, разработку генетических паспортов, редактирование человеческой ДНК, замену естественной эволюции человека автоэволюцией, омоложение человека с помощью фермента теломеразы. Следует отметить, что ничем не ограниченные генетические эксперименты, могут привести к получению новых типов нуклеиновых кислот, биологические свойства и последствия которых нельзя предсказать заранее [4].

Еще одной проблемой генетики из области морально-этических является евгеника - учение об улучшении человеческого рода. Самым известным в истории случаем реального воплощения в жизнь евгенического проекта была нацистская Германия. Ее опыт по расовой гигиене, эксперименты над людьми, уничтожение «нежелательных» социальных групп обернулся истреблением целых народов - поляков, евреев (холокост), граждан СССР на оккупированной территории. Другим примером служит принятие в 1907 г. в штате Индиана США первого нормативного акта, узаконившего принудительную стерилизацию «неполноценных» американцев, к которым относились люди с имбецильностью и идиотией, преступники-рецидивисты и насильники.

Эстетическое воспитание - формирование восприимчивости к красоте генетической науки, стройности ее закономерностей, выражающихся с математической строгостью.

Формированию эстетических чувств при изучении курса генетики способствуют окраска и форма изучаемых объектов. Нередко это красивые виды растений и животных. Например, изменчивость окраски и формы цветков львиного зева, наследование окраски цветков у душистого табака или петунии при неполном доминировании аллельных генов, фенотипическое проявление кодоминантного взаимодействия генов у цветков камелии японской, комплементарное взаимодействие неаллельных генов у волнистых попугайчиков. Рассматривая изменчивость окраски раковин морского гре- бешка, можно продемонстрировать картину Боттичелли «Рождение Венеры». Орнаменты, похожие на схемы при множественном кроссинговере, можно видеть в качестве украшений многих памятников архитектуры Узбекистана: на минарете мечети Биби-Ханум и на внутренней стене усыпальницы Тамерлана - мавзолея Гур-Эмир в Самарканде, а также на стене ханского гарема в Хиве. Авторы нескольких монументальных скульптур, вдохновленные красотой молекулы ДНК, посвятили ей свои произведения. Один такой монумент стоит на проспекте в Пекине [14].

Красоту вызывают не только окраска и форма живых организмов, но и математические модели и выражения, которые прослеживаются в законах Г. Менделя, Т. Моргана, Харди-Вайнберга; закономерностях модификационной изменчивости, соотношении потомков при различных видах скрещиваний (например, анализирующем скрещивании), а также взаимодействии аллельных и неаллельных генов. Нельзя не любоваться логикой, стройностью и изяществом генетических задач и их решений, схем скрещиваний и родословных.

Формирование культуры здоровья - осознание ценности жизни, ответственное отношение к своему здоровью и здоровью окружающих; выработка установки на здоровый образ жизни, осознание последствий и неприятие вредных привычек, соблюдение правил безопасности.

Этому направлению воспитания способствует изучение вопросов, касающихся репродуктивного здоровья человека и заболеваний, передающихся половым путём (ЗППП). Снижению показателей ЗППП способствует половое просвещение населения. Верными средствами от венерических заболеваний являются моногамность и супружеская верность.

Широкие возможности для формирования культуры здоровья предоставляет тема «Наследственные заболевания человека», в которой раскрываются причины, проявления, последствия и профилактика генетических заболеваний человека. Одним из эффективных методов предупреждения наследственных заболеваний является медико-генетическое консультирование, которое позволяет предсказать риск появления в потомстве больного ребенка.

При изучении темы «Генетические основы патогенеза, диагностики и профилактики вирусных инфекций» затрагиваются не только вопросы генетики вирусов, их жизненные циклы, но и правила предупреждения распространения и профилактики вирусных инфекций, в том числе COVID-19. Это способствует формированию у учащейся молодежи социальной ответственности и компетентности. 
Осознанию последствий вредных привычек и их неприятию содействует содержание темы «Генетическая изменчивость, ее виды». Так, злоупотребление загаром и увлечение соляриями может привести к преждевременному старению кожи, усугублению заболеваний щитовидной железы, сердечно-сосудистой и нервной систем, образованию злокачественных новообразований, в частности меланомы. В пораженной ультрафиолетом ДНК возникают «сшивки» тиминовых оснований (тиминовые димеры), которые искажают ее структуру [15].

Знакомство с мутагенами - факторами, вызывающими мутации, способствует раскрытию вредного воздействия на организм употребления алкоголя, наркотиков, курения. Содержащиеся в них вещества нередко обладают мутагенным и канцерогенным эффектами.

Трудовое воспитание - развитие интереса к профессиям, связанным с генетикой и генетическими технологиями, уважение к труду генетиков.

Генетика - одна самых перспективных и бурно развивающихся наук, поэтому профессии, связанные с ней, являются весьма перспективными, их смело можно назвать профессиями будущего. Отметим лишь некоторые из них.

Ученый-генетик - изучает строение молекулы ДНК, законы и механизмы наследственности и изменчивости, а также методы управления ими.

Врач-генетик - занимается диагностикой и лечением наследственных заболеваний, первопричинами которых являются генные, хромосомные и геномные мутации, предупреждает и определяет риски развития этих болезней; помогает скорректировать образ жизни и рацион питания, подобрать лекарственные препараты и комплекс оздоровительных упражнений и процедур; может определить степень родства между людьми, помочь в идентификации личности, спрогнозировать предрасположенность человека к тому или иному виду спортивной или профессиональной деятельности.

Генный инженер - специализируется на изменении свойств живых организмов на основе манипуляций с генами. Он способен непосредственно вмешиваться в генетический аппарат, имеет возможность оперировать любыми генами, синтезировать их, переносить от одного вида другому и произвольно комбинировать.

ИТ-генетик - программирует геном под заданные параметры. Это позволит осуществлять генотерапию, т.е. вносить в генетический аппарат человека такие изменения, которые позволят бороться с наследственными заболеваниями.
Клинический биоинформатик - интерпретирует генетическую информацию с использованием специализированных информационных систем и программного обеспечения, анализа больших данных, осуществляет компьютерное моделирование процессов течения болезни на генном уровне, что позволяет максимально индивидуализировать лечение пациентов - переходить от обычной медицины к персонализированной.

Знания генетики необходимы сотрудникам генетических лабораторий, биоинженерам, биоинформатикам, биотехнологам, экспертам-криминалистам и селекционерам.

Трудовое воспитание, помимо профессиональной ориентации, подразумевает формирование уважительного отношения к труду людей, связанных с генетикой и генетическими технологиями, результатам их труда. В российском обществе сложилось крайне негативное отношение к продуктам, в состав которых входят генетически модифицированные организмы (ГМО). Хотя, их вред не доказан и существенно преувеличен средствами массовой информации. Продукты без ГМО, как правило, всего лишь маркетинговый ход. Следовательно, мы не доверяем специалистам, а значит, не уважаем их труд.

Другой пример - нежелание людей вакцинироваться. Как уже ранее отмечалось, некоторые вакцины создаются с применением генетических технологий. Данный факт можно рассматривать как недоверие создателям вакцин, неуважение к их труду. Незнание, необоснованные страхи, излишняя самоуверенность порождают всевозможные домыслы и фантазии о вреде вакцинации, что приводит к колоссальным человеческим жертвам, разрушению экономики, снижению качества жизни.

Экологическое воспитание - применение генетических знаний для решения задач в области экологии и охраны окружающей среды. Его конечным результатом должна стать экологическая культура личности.

Реализации экологического воспитания способствуют вопросы, связанные с эколого-генетическими моделями и симбиогенетикой, влиянием различных факторов на генетические процессы и мутагенезом, генетической токсикологией и генетикой устойчивости к устойчивости к факторам среды [16].

Ценности научного познания - ориентация в деятельности на современную систему научных представлений об основных закономерностях наследственности и изменчивости. Овладение основными умениями исследовательской деятельности в области генетики.

Формированию ценностей научного познания способствует знакомство с новейшими достижениями ге- 
нетики и генных технологий, современными методами исследований. Обычными для понимания должны стать такие понятия, как полимеразная цепная реакция (ПЦР), электрофорез, секвенирование, генная и клеточная инженерия.

Овладение основными умениями исследовательской деятельности в области генетики намечено в ходе лабораторных и практических работ: «Выделение ДНК», «Генетический анализ закономерностей наследования при моногибридном скрещивании», «Генетический анализ закономерностей наследования при дигибридном скрещивании», «Описание фенотипа», «Изучение модификационной изменчивости», «Полиплоидия и особенности наследования у автополиплоидов», «Составление модельных панмиктических популяций при заданных частотах гамет», «Составление идиограммы человека, её анализ», «Генетическая дактилоскопия», «Тест на отцовство». Следует отметить, что некоторые из них проводятся на базе Педагогического технопарка «Кванториум» имени В.Ф. Волкодавова Самарского государственного социально-педагогического университета.

\section{ЗАКАЮЧЕНИЕ}

Курс генетики обладает большими возможностями для осуществления различных направлений воспитания. Позволяет реализовать один из важнейших дидактических принципов - принцип воспитывающего обучения. Способствует не только воспитанию самих студентов, но и готовит их к реализации воспитательной функции в качестве будущих учителей биологии.

\section{ЛИТЕРАТУРА}

1. Генетическое образование: как сейчас изучают генетику в школах. [Электронный ресурс] URL: https://prosv.ru/news/show/6166.html (дата обращения: 03.11.2021).

2. Совещание о развитии генетических технологий в России. [Электронный ресурс] URL: http://www.kremlin.ru/events/president/transcripts/63350 (дата обращения: 03.11.2021).

3. Примерная рабочая программа курса «Генетика» (для 10-11 классов образовательных организаций. - М.: Институт стратегии развития образования PAH, 2021. $-45 \mathrm{C}$.

4. Моссэ И.Б., Кильчевский А.В. Этические проблемы генетики XXI века // Наука и инновации. - 2017. - № 3 (169). - С. $23-27$.

5. Примерная программа воспитания. Одобрена решением от 02.06.2020. Протокол № 2/20. [Электронный ресурc] URL: https://fgosreestr.ru/registry/ primernaja-programma-vospitanija/ (дата обращения: 04.11.2021).

6. Федеральный государственный образовательный стандарт основного общего образования. Утвержден приказом Министерства просвещения Российской Федерации от 31 мая 2021 г. № 287. [Электронный ресурc] URL: https://www.garant.ru/products/ipo/prime/doc/401333920/ (дата 0бращения: 04.11.2021).

7. Федеральный закон от 5 июля 1996 г. N 86-Ф3 «0 государственном регулировании в области генно-инженерной деятельности» (с изменениями и дополнениями). [Электронный ресурc] URL: https://base.garant.ru/10135402/ (дата обращения: 04.11.2021).

8. Федеральный закон от 20 мая 2002 г. N 54-Ф3 «0 временном запрете на клонирование человека» (с изменениями и дополнениями). [Электронный ресурc] URL: https://base.garant.ru/184467/ (дата обращения: 04.11.2021).

9. Федеральный закон от 30 декабря 2020 г. № 492-Ф3 «0 биологической безопасности в Российской Федерации» [Электронный pecypc] URL: https://www. garant.ru/products/ipo/prime/doc/400056868/ (дата обращения: 04.11.2021).

10. Дудинцев В.Д. Белые одежды. - М.: Книжная палата, 1988. - 688 с.

11. Гранин Д.А. Зубр: повесть. - Л.: Советский писатель, 1987. - 287 с.

12. Жимулев И.Ф. Общая и молекулярная генетика: учеб. пособие для вузов / под ред. Е.С. Беляева, А.П. Акифьева. - Новосибирск: Сиб. унив. изд-во, 2006. - 479 с.

13. Saito H., Semenov A.A. How Was Biology Education Reformed in Russia after the Lysenko Period? // Historia Scientiarum. - 2019. - Vol. 28, No 2. - P. 152-178.

14. Захаров-Гезехус И.А. Красота генетики // Химия и жизнь. - 2011. - № 11. - С. 52-53.

15. Факторы среды и генетическое здоровье человека: книга для внеклассного чтения учащихся старших классов / сост. Л.И. Лушина, А.А. Семенов. - Самара: Изд-во СамГПУ, 2002. - 115 с.

16. Инге-Вечтомов С.Г. Генетика с основами селекции: учебник для студентов высших учебных заведений. - СПб.: Изд-во Н-Л, 2010. - 720 с. 